\title{
Learning Declarative Knowledge in Special Education Treatment Group
}

\author{
Rickard Östergren \\ Linköpings University, Sweden \\ Marie Ringborg Lindgren \\ Norrköpings Municipality, Sweden \\ Britt-Marie Lindgren \\ Norrköpings Municipality, Sweden \\ Joakim Samuelsson (Corresponding Author) \\ IBL Linköpings universitet \\ S-581 83 Linköping, Sweden \\ E-mail: Joakim.samuelsson@ liu.se
}

Received: November 30, 2017

Accepted: December 28, 2017 Published: February 20, 2018

doi:10.5296/jet.v5i1.12702

URL: http://dx.doi.org/10.5296/jet.v5i1.12702

\begin{abstract}
An organizing structure that in recent years has had a major impact on how to work with students who don't respond to regular instruction is Response to Intervention (RTI). Efforts in RTI are divided into three different tiers of instruction: primary, secondary and tertiary. In our study, we investigate the impact of intensive secondary-tier instruction on students' knowledge of basic combinations of digits in addition. We also focus on how the students develop their use of more advanced calculations in addition during the intervention.

The results showed that students became faster at performing simple addition tasks, which indicates that their fluency - declarative knowledge - developed during the intervention phase. Our results thereby strengthen suggestions that a secondary-tier intervention level should take place in a small group of students 20-40 minutes four to five times a week. Meanwhile, the students developed their ability to solve two-digit arithmetic tasks in addition and subtraction, which could be explained by the fact that students had automated simple number combinations and thus could focus on the calculation procedure.
\end{abstract}

Keywords: Learning, Declarative knowledge, Mathematics, Special education, RTI 


\section{Introduction}

Young children encounter a variety of numerical phenomenon that are essential to master in a numerical world. The most obvious of these phenomena are numeric words such as one, two, three, and so on. Children also need to learn calculation techniques such as addition, subtraction, multiplication and division (Butterworth, 2005). Moreover, mastering basic combinations of digits is essential knowledge for performing calculations (Hudson \& Miller, 2006; Dowker, 2012). Students who do not learn these skills in regular instruction need more or different education - special education. How special education should be organized and implemented has been a subject of debate among researchers and teachers (e.g. Fuchs \& Fuchs, 2001; Grosche \& Volpe, 2013).

An organizing structure that in recent years has had a major impact on how to work with students who don't respond to regular instruction is Response to Intervention (RTI). The basic idea of RTI is that teachers identify students' problems and prevent the students from developing difficulties (Grosche \& Volpe, 2013). Efforts in RTI are divided into three different tiers of instruction: primary, secondary and tertiary (Fuchs \& Fuchs, 2001). Primary instruction is directed at everyone in the group of students (such as an entire class); the students who do not perform as expected and need more support then move to the secondary tier. Instruction on this level is supplements the basic instruction and is not a replacement for it. It usually takes place in small groups of students for 20-40 minutes, four to five times a week (Gersten et al., 2009). Students who do not respond positively to this intervention require more individual and intensive teaching. This is done outside of regular math classes and is often carried out by special education teachers; it tends to take 30 minutes 4-5 times a week for ten weeks (Gersten et al., 2009). Earlier research show that this type of intensive instruction, based on the student's learning profile, is more effective for students who are struggling with mathematics than regular mathematics teaching (Re et al., 2014).

In our study, we investigate the impact of intensive secondary-tier instruction on students' knowledge of basic combinations of digits in addition. We also focus on how the students develop their use of more advanced calculations in addition during the intervention.

\subsection{Arithmetic Abilities and Its Significance for Mathematics Development}

Solving tasks in arithmetic requires different competencies in mathematics (Hudson \& Miller, 2006; Dowker, 2012). Hudson and Miller (2006) mention three different competencies linked to arithmetic: a) declarative; b) procedural; and c) conceptual knowledge. Declarative knowledge means having knowledge that can be retrieved directly from memory without hesitation: simply 'knowing something' (Hudson \& Miller, 2006). In mathematics, for example, it can involve reading a clock quickly, knowing how much a two-pence coin is worth, or having automated a combination of simple addition tasks. Hudson and Miller (2006) describe procedural knowledge as a strategy in which the student makes an analysis of the various stages and the order in which specific arithmetic tasks are to be carried out. A student with conceptual knowledge can see the relationships between numbers, and is able to use the knowledge of these relationships when solving tasks in arithmetic (Dowker, 2012). Thus, being able to deduce or quickly pick up basic combinations of digits, together with an 
understanding of the meaning behind the positioning of the digits as well as of the different calculation operations, is a foundation of the management of the four operations using multi-digit numbers (McIntosh, 2008).

The advantage of having good declarative knowledge regarding combinations of digits is that students do not have to use mental resources to carry out calculations of basic combinations; instead, the student can focus on other parts of the task such as the procedure. A student is expected to learn 200 basic addition combinations (such as $3+2$ and 13+2) and 200 subtraction combinations. For a child to be considered fluent, he or she must give at least 30 correct answers per minute (Hudson \& Miller, 2006) to this type of task. The metric used is digits correct per minute (DCPM).

Previous studies have shown that a student's fluency (declarative knowledge) in solving simple arithmetical tasks predicts learning in future, more advanced mathematics (Hassel Bring, Goin \& Sherwood, 1986; Robinson et al., 2002; Gersten, Jordan, \& Flojo, 2005; Rathmell \& Gabriele, 2011). Fuchs et al. (2006) have shown that there is a strong correlation between the automation of combining digits within the range from 0 to 12 and students' ability to calculate double-digit additions and subtractions, as well as problem solving.

Fluency does not necessarily mean that the digit combinations are automated. The student can also have developed strategies that they use fluently. Problems reproducing mathematical facts - whether automated or using strategies - is a common characteristic of students with difficulties in mathematics (Geary, Hoard, \& Bailey, 2012).

By working with combining digits in regular instruction and by using structured exercises, students will increase their automation (Hudson \& Miller, 2006). Other researchers argue that students should not solve tasks in a specific amount of time (Boaler, 2015), since students can experience math anxiety and performance requirements when a test is timed Tsui and Mazzocco (2006).

In summary, declarative knowledge - automation of basic combinations with respect to addition - is important solving arithmetical tasks. A student's declarative knowledge also predict future performance in more advanced mathematics. Thus, declarative knowledge in arithmetic is an important component of knowledge in mathematics learning.

\section{Purpose and Questions}

The purpose of this study was to describe and analyze how a secondary-tier special education intervention affects the progress in arithmetic of pupils in grade 4 with special needs in mathematics (students 10 years old). The following questions will be answered:

1) To what extent will students with special needs in mathematics develop their declarative knowledge with respect to addition, when participating in the intervention?

2) To what extent will students with special needs in mathematics develop their performance in solving two-digit addition and subtraction tasks, when participating in the intervention? 


\section{Method}

\subsection{Participant}

Four students in grade 4 (three boys and one girl) in need of special education in mathematics participated in the study. To be selected for the intervention, the following criteria were applied: (a) the student did not attain a passing grade on the year 3 national test in mathematics; (b) the student had a documented problem in mathematics; and (c) the student displayed low levels of fluency on tests and performed between 0 and 10 correct numbers in a minute.

All students were born in Sweden and went to a local school in an average-sized city in Sweden. The school was located in a residential district.

The intervention consisted of 15 minutes of daily additional instruction/practice before scheduled instruction at the school began. All instruction was carried out by a special education teacher at the school and lasted for 9 weeks, with a follow-up after 3 weeks. Teaching was carried out with computer-aided instruction, which is often recommended for this student category and for mathematics learning (Ok \& Bryant, 2015). In this case, the teacher gave out assignments to the students, which consisted of groups of math tasks (around 20 in total) with different simple addition combinations. Students worked on their assignments, and the teacher helped the students who needed support. For the first two weeks, the teacher selected as broad a range of exercises as possible. The purpose was so that the teacher could discover which combinations were most difficult for the students. After the first two weeks, the teacher selected more targeted exercises for each student, based on that student's needs. For the final two weeks of the intervention, the students repeated the same exercises they practiced the first two weeks, thus having a chance to encounter all the combinations once again.

Examples of assignments included addition up to 10, addition up to 15, or adding seven or eight. All assignments were aimed at developing students' declarative knowledge automating the basic combinations of digits. The students used computers (or iPads, in our case) because previous studies have shown that motivation may thereby be increased among students with special needs in mathematics (Samuelsson, 2006; Ok \& Bryant, 2015). Another reason is that computers offer great opportunities as regards individualization, task difficulty levels, and the amount of exercises.

A guiding principle throughout the entire project was the practical contribution to students' learning, studied with scientific methods. From an RTI perspective it meant that the teacher, in collaboration with the researchers, took note of problematic things in practice, which were then corrected. The following issues in the project were important ones: (a) how the work was introduced; (b) management of the technology; (c) introducing a timing aspect; and (d) changing the organization.

When the students were introduced to the intervention, the teacher presented the project as an offer that the school had invested in them. Management of the technology was another important aspect that which, the teacher noted, affected students' opportunities to work with 
mathematics as quickly as possible. The teacher therefore tried to add the fluency test after training, instead of before practice; this proved to be positive for performance on the fluency test. Students were given the chance to warm up both fingers and brain. A third important aspect that helped students develop their fluency was the teachers' reminders to complete the assignment as quickly as possible. A fourth important aspect that affected students' learning was their location in the classroom. Some student had difficulty concentrating at specific places in the room. When the teacher asked them to sit at a location where they could concentrate, they worked more, concentrated harder, and started performing better on the fluency test.

\subsection{Research Design}

This is a multiple-probe design across participants. Experimental case studies (single-case design) has a long tradition, particularly in behavioral analysis (Kazdin, 2011). The overall aim of this method is the same as in experimental group studies: to gain knowledge of what causes a certain change in the behavior of people. It has been argued that the experimental case study methodology can be a very useful method of research in specific practices (Kazdin, 2011). The method can also be used as a complement to studies of groups where effects of education as well as special education are examined, thereby building an evidence-based practice within the school area (Horner, Carr, Halle, Odom, \& Wolery, 2005; Plavnick \& Ferreri, 2011).

There are several design options to choose from; two common ones are $\mathrm{ABAB}$ design and multiple baseline design (Kazdin, 2011). In this study, we used the latter. In multiple baseline design, multiple points (in our case, the students' performance before the intervention) form a baseline to be used as a comparison to the intervention phases.

The multiple baseline design uses a number of key concepts.

Depending Measure: This measure is used to make visible what the intervention is intended to change, in our case fluency test scores.

Baseline: This line is the result of the dependent measure (fluency test scores) before intervention is initiated. Should be at least two measuring points (Kazdin, 2011).

Intervention phase: The phase where the students practice and take tests.

Follow-up phase: The phase after the intervention phase. Students have stopped practicing, but still take fluency tests.

\subsection{Mathematics Measurement}

To obtain a stable baseline before the intervention started, fluency tests on automation of addition combinations were carried out on 6 to 8 occasions using iPads. The tests were made in one minute and contained simple addition tasks such as $3+7,8+7,7+5$, and $6+6$. We used four equivalent variants of tests that were randomly distributed to students each day. The students also took a five-minute test of two-digit addition and subtraction tasks each 
week, consisting of 25 addition tasks and 25 subtraction tasks. The students solved the addition tasks first and then the subtraction tasks.

\subsection{Analysis}

To understand what effect the intervention had on students' declarative knowledge regarding basic addition combinations, a visual analysis of the data was conducted. This type of analysis provides the researcher with the opportunity to see the level of students' performance at different times, trends in development, variability, and immediacy (Kazdin, 2011). In addition to the visual aspect we calculated Tau-U, which is a measure of how the various phases are separated. To test the mean differences between pre-test and post-test on two-digit addition and subtraction tasks test, we used a T-test.

\section{Results}

The results are presented in two sections: a) Development of declarative knowledge; and b) Development of arithmetic knowledge with respect to addition and subtraction.

\subsection{Development of Declarative Knowledge}

The results show all students displaying a positive trend over time; the performance between the measurements varied both negatively and positively; and some students responded more quickly to intervention than others. We also noticed that there seemed to be a pattern that recurred in terms of student performance over time: the intervention phase seemed to have an initial phase, a middle phase and a final phase. Therefore, we will discuss the entire intervention phase for the initial phase ( 2 weeks), the middle phase ( 4 weeks), and the final phase ( 3 weeks) to illustrate what happened during the intervention phase.

Student 1. The baseline for student 1 consisted of six measurements $(M=8.17$, variation $=$ 6-10). After the intervention was carried out, the student's performance improved in relation to the baseline. The average value during the initial phase is $M=9.89$, variation $=8-13$. The effect of the intervention seems to have come about a week after the intervention was carried out, when the student's performance increased three points. In the middle phase, the student varied between 10 and 15 correct answers on the fluency test. The visual analysis provides no support for development during this phase; the student's performance varied too much for any trend to be noticeable. However, the student's mean scores during this period displayed higher results in the middle phase than in the initial phase $(M=11.83)$. In the final three weeks, the student performed significantly higher than during the middle phase $(M=18.54$, variation $=15-22$ ). Finally, we can see that the student developed over time - from 8 to 22 points on the fluency test during the intervention phase. The learner did not perform on the same level in the follow-up tests (about 4 weeks after the intervention) as at the end of the intervention phase. However, the follow-up phase $(M=16.67$, variation 13-19) was better than the middle phase.

Student 2. The baseline consisted of seven measurements $(M=5.57$, variation $=4-8)$. It was one week longer for student 2 than for student 1, however; illness affected the number of measurements during the base line. Performance during the initial phase varied widely $(M=9$, 
variation $=4-15)$. The student was very dissatisfied with his handling of the iPad, which could be an explanation for the variety during this period. In the beginning of the middle phase, the student tried another strategy and moved the cursor by using the arrow keys, rather than touching the screen on the iPad. The student was not satisfied with the strategy and returned to the original strategy, while the teacher tried to help the student practice handling the iPad. During the middle phase, the pupil performed on a lower level than during the initial phase $(M=7.85$, variation $=2-14)$, which could be explained by how they handled the technology. The final phase was significantly better than the earlier phases $(M=17.84$, variation $=15-22$ ). The follow-up phase showed that student performed at a lower level than at the final phase. Studied across the intervention phase, there was a development of fluency over time; the student had moved from a starting value of 8 to 22 by the end of the intervention.

Student 3. The base line consisted of six measurements $(M=10.17$, variation $=9-11)$. The student responded relatively quickly to the intervention, although performance varied greatly compared to baseline $(M=11.85$, variation $=6-18)$. In the next phase - the middle phase -performance became more stable. Visual analysis also provided an indication of positive development in this phase $(M=11.15$, variation $11-19)$. The trend continued during the final phase as well $(M=20.30$, variation $=16-24)$. Thus, during the intervention phase, the student developed from a starting value of 6 to 24 points on the fluency test. The follow-up phase showed that this student performed at the same level as in the final phase of the intervention $(M=19.5$, variation $19-20)$.

Student 4. The baseline for student 4 consisted of eight measurements $(M=7.25$, variation $=$ 6-9). After the intervention was carried out, it is difficult to say whether the student was affected by the intervention during the initial phase $(M=8.5$, variation $=5-10)$, although the mean value is slightly higher. In the middle phase, we once again can see a trend over time; the students seemed to improve steadily on the fluency test $(M=13$, variability $=10-15)$. Further development could be seen in the final phase $(M=15.5$, variation $=13-16)$. The development during the intervention was 8 points, from 10 to 18 . In the follow-up phase, it could be seen that the student's performance had declined. 


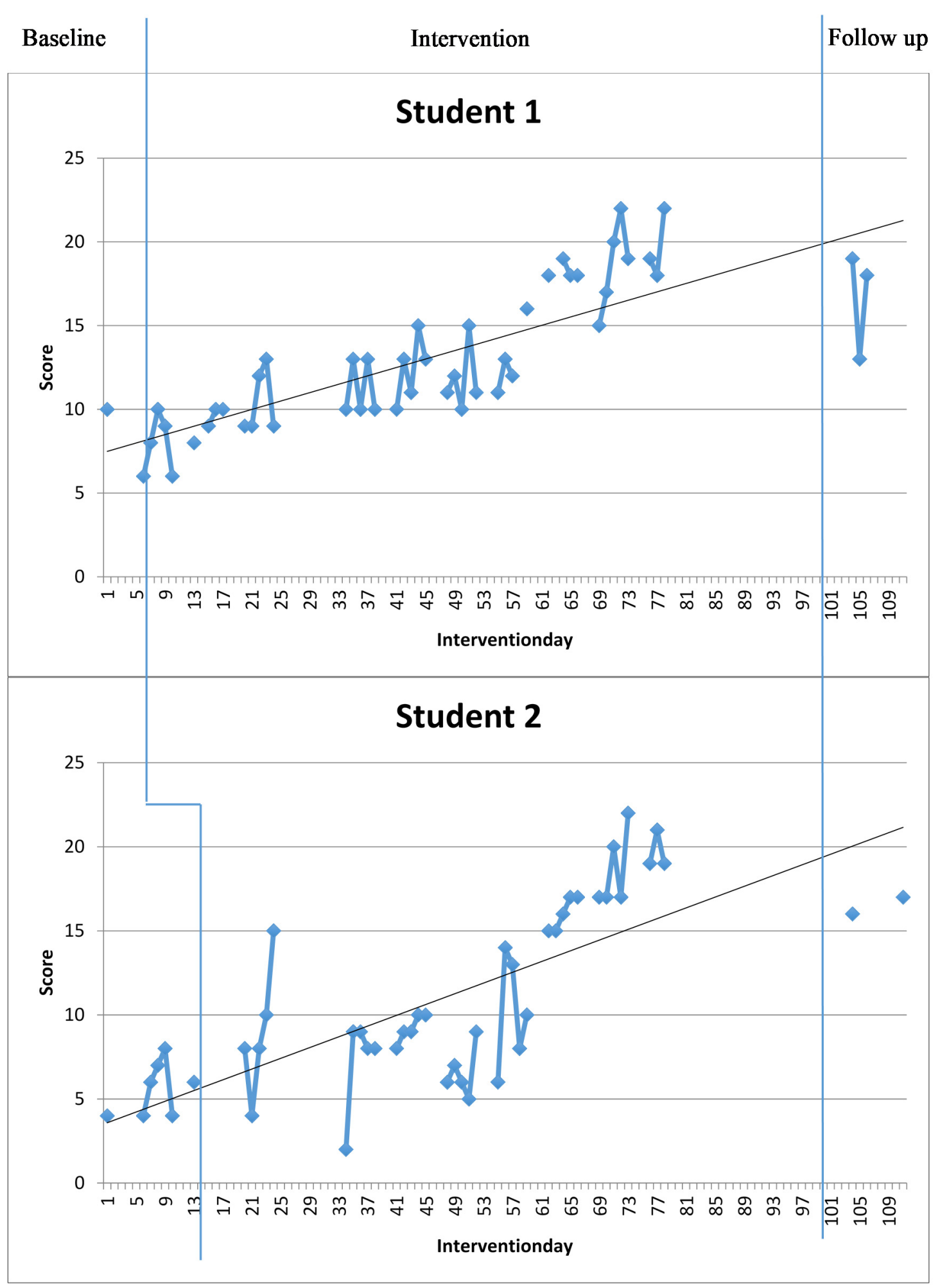

Figure 1. Fluency performance for student 1 and student 2 


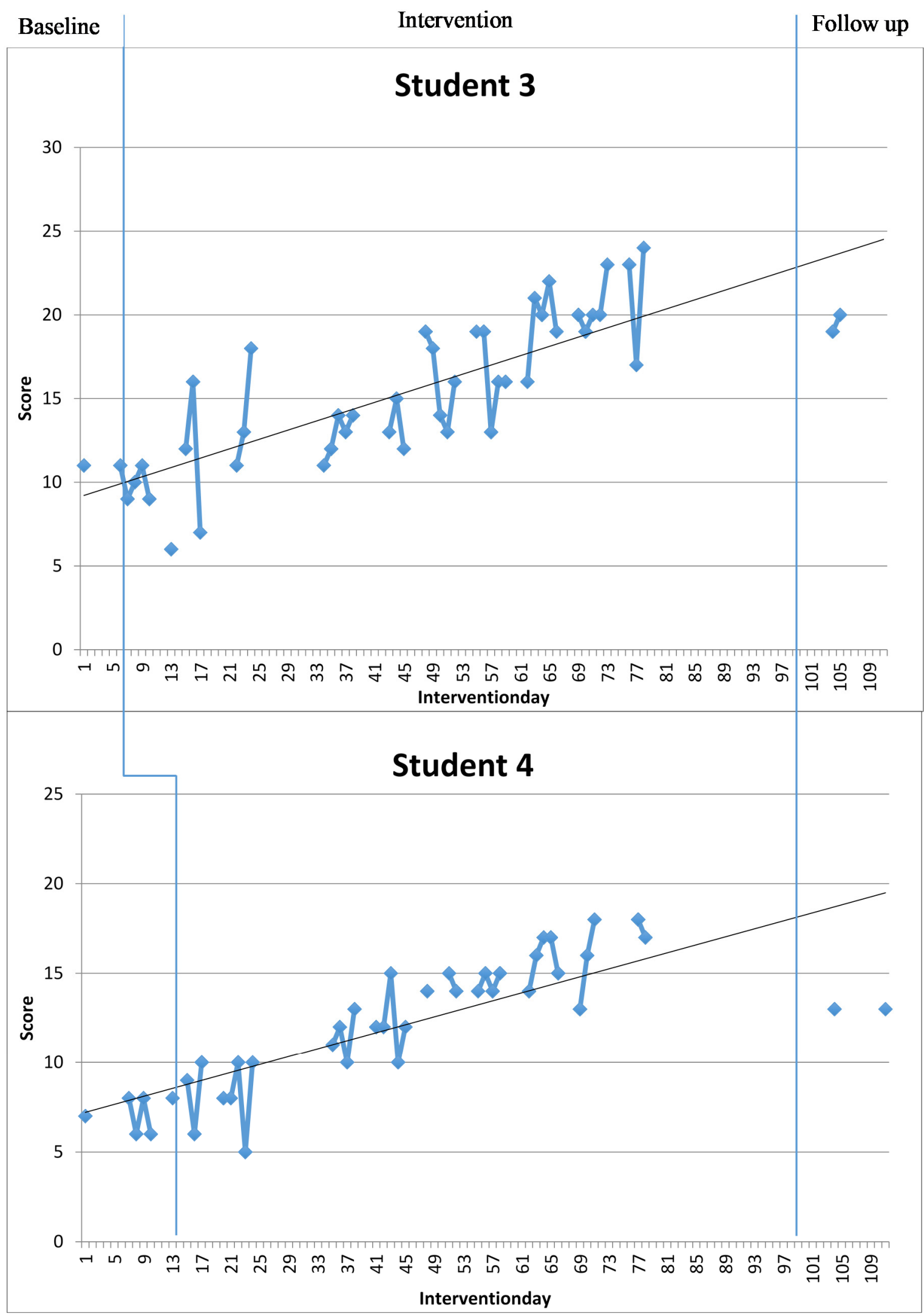

Figure 2. Fluency performance for student 3 and student 4 
To sum up the results, the visual analyses show that all students developed their declarative knowledge as regards simple addition tasks. We can also see that the students responded differently to the intervention. Two students (Students 2 and 3) responded immediately to the intervention. One student (Student 1) responded after one week, and one student (Student 4) responded after two weeks. Thus, the results indicate that students responded to the intervention, but that there were individual differences in response time. In the middle phase, two patterns have been noted: a) the results from the middle phase are at a level equal to or higher than the initial phase (Students 1 and 2); and b) the students developed constantly throughout the phase (Students 3 and 4). Another pattern is that the final phases for all students were significantly better than the earlier phases. The results of the follow-up phase (lower than the final phase) illustrates that declarative knowledge needs to be practiced regularly.

To further study the effect of the intervention, Tau- $U$ was estimated (see Table 1), which showed that there was an overlap of $12-23 \%$ between the baseline and the intervention phase.

The greatest overlap was found with student 2. One explanation may be that the student was trying to learn how to use other "keys" to move around the screen. When it did not work, the student became stressed, which produced poorer results.

Table 1. Tau $U$ is the percent of data between baseline and intervention phase that do not overlap

\begin{tabular}{llll}
\hline Student & Tau-U & CI $90 \%$ & p-value \\
\hline 1 & .83 & $0: 41$ to $1: 25$ & .001 \\
2 & .77 & $0: 38$ to $1: 17$ & $<.001$ \\
3 & .88 & $0: 45$ to $1: 29$ & $<.001$ \\
4 & .87 & $0: 51$ to $1: 24$ & $<.001$ \\
\hline
\end{tabular}

\subsection{Development of Arithmetic Knowledge}

Table 2 presents students' performance on the weekly arithmetic tests. The analysis shows that there was a significant difference between pre- and post-measurement with respect to subtraction, $t(3)=-4.04 ; p=.027$. This difference could be explained, however, by the fact that students completed the addition tasks first and then the subtraction tasks. Faster, effective mastering of addition tasks may have given them greater opportunity to solve additional subtraction tasks. 
Table 2. Mean values for each student, pre-test and post-test results with respect to addition and subtraction

\begin{tabular}{lllll}
\hline Student & Addition (pre-test) & $\begin{array}{l}\text { Addition } \\
\text { (post-test) }\end{array}$ & $\begin{array}{l}\text { Subtraction } \\
\text { (pre-test) }\end{array}$ & $\begin{array}{l}\text { Subtraction } \\
\text { (post-test) }\end{array}$ \\
\hline 1 & 18 & 21.5 & 3.5 & 10.5 \\
2 & 21.5 & 22 & 1 & 18.5 \\
3 & 20 & 22 & 0 & 13 \\
4 & 16 & 23 & 0 & 6 \\
\hline
\end{tabular}

\section{Discussion}

The aim of this study was to describe and analyze how secondary-tier special education intervention affected the progress of pupils with special needs in mathematics in grade 4 . The results showed that students became faster at performing simple addition tasks, which indicates that their fluency - declarative knowledge - developed during the intervention phase. Our results thereby strengthen suggestions that a secondary-tier intervention level should take place in a small group of students 20-40 minutes four to five times a week (Gersten et al., 2009).

Meanwhile, the students developed their ability to solve two-digit arithmetic tasks in addition and subtraction (e.g. Fuchs et al., 2006), which could be explained by the fact that students had automated simple number combinations and thus could focus on the calculation procedure. Since previous studies have shown that a student's fluency predicts future math performance (Hasselbring, Goin, \& Sherwood, 1986; Robinson et al., 2002; Gersten, Jordan, \& Flojo, 2005; Rathmell \& Gabriele, 2011), the measured improvement of the student's fluency will be important for their continued learning of mathematics.

There are several factors that, individually or collectively, are a partial explanation for the development of fluency and procedural knowledge. The extent to which each process affected the outcome cannot be specified in this study. An important aspect of the RTI structure that should not be underestimated is an analytical teacher who sees what is happening in the classroom and makes appropriate corrections to the instruction (Grosche, \& Volpe, 2013). The following activities were noticed and managed by the teacher: a) introducing the work as an offer; b) supporting operation of the technology; c) introducing time as an important aspect in the training sessions; and d) changing the organization, which led to improvements for the student. Although we cannot speculate on the causes of the development, we can conclude that there had been a development of key mathematical 
abilities during the period of intervention. The conditions we have reported are thus favorable for students' development.

Apart from the positive trend over time, the results show that students had different development patterns. Some responded immediately to the intervention, others had a delay; some developed continuously, while others reached a plateau. The results illustrate that students are different and learn differently, but the intervention conditions had a positive effect on students' mathematics performance. Follow-up tests also showed that this ability needs to be practiced regularly since performance dropped when students stopped exercising.

\subsection{Limitations and Suggestions for Further Research}

There are a number of limitations to the current study. One such limitation was the point at which the measurements of the baseline would stop. We took this decision with respect to practical reasons not determined by the appearance of the base line. Starting the students on active intervention was more important. For ethical reasons, it was not possible to do otherwise. Another limitation is the technical problems that made it difficult for students to respond. The teacher took careful notes whenever a technical problem appeared, and tried to support students who had these problems.

There is an ongoing debate within the field of mathematics education regarding how students should learn the subject. The discussion relates to whether the student should first practice their procedural ability and then acquire understanding, or if the student should acquire understanding first and then be able to practice procedures a little less. What this discussion does not address is how these two methods affect students with special needs in mathematics and their learning. Could these students obtain positive learning results in terms of math skills if they automate their knowledge, without understanding? Is there any method that is more effective for students with special needs in mathematics as regards age and tiers of RTI education (primary, secondary and tertiary) (Fuchs \& Fuchs, 2001)? And how are students with special needs affected if they work with mathematics against time? Some researchers argue that work against time can create math anxiety (Boaler, 2015). Thus, the effect of different methods on students with special needs should must be investigated further.

\section{References}

Boaler, J. (2015). Fluency Without Fear: Research Evidence on the Best Ways to Learn Math Facts. Retrieved from http://youcubed.stanford.edu/fluency-without-fear

Butterworth, B. (2005). The development of arithmetical abilities. Journal of Child Psychology and Psychiatry, 1, 3-18. http://dx.doi.org/10.1111/j.1469-7610.2005.00374.x

Dowker, A. (2012). Individual differences in arithmetic: implications for psychology, neuroscience and education. New York: Psychology Press.

Fuchs, L. S., Fuchs, D., Compton, D. L., Powell, S. R., Seethaler, P. M., Capizzi, A. M., \& Fletcher, J. M. (2006). The cognitive correlates of third-grade skill in arithmetic, algorithmic computation, and arithmetic word problems. Journal of Educational Psychology, 98(1), 29-43. http://dx.doi.org/10.1037/0022-0663.98.1.29 
Fuchs, L. S., \& Fuchs, D. (2001). Principles for the Prevention and Intervention of Mathematics Difficulties. Learning Disabilities Research and Practice, 16(2), 85-95. http://dx.doi.org/10.1111/0938-8982.00010

Geary, D. C., Hoard, M. K., \& Bailey, D. H. (2012). Fact Retrieval Deficits in Low Achieving Children and Children With Mathematical Learning Disability. Journal of Learning Disabilities, 45(4), 291-307. http://dx.doi.org/10.1177/0022219410392046

Gersten, R., Beckmann, S., Clarke, B., Foegen, A., Marsh, L., Star, J. R., \& Bradley, W. (2009). Assisting Students Struggling with Mathematics: Response to Intervention (RTI) for Elementary and Middle Schools. NCEE 2009-4060. What Works Clearinghouse.

Gersten, R., Jordan, N. C., \& Flojo, J. R. (2005). Early Identification and Mathematics Difficulties. Journal of Learning Disabilities, 38(4), 293-304.

Grosche, M., \& Volpe, R. J. (2013). Response-to-intervention (RTI) as a model to facilitate inclusion for students with learning and behaviour problems. European Journal of Special Needs Education, 28(3), 254-269. http://dx.doi.org/10.1080/08856257.2013.768452

Hassel Bring, T. S., Goin, L., \& Sherwood, R. D. (1986). The effects of computer based drill-and practice on automaticity: Technical report. Nashville, TN: Vanderbilt University, Learning Technology Center.

Horner, R. H., Carr, E. G., Halle, J., McGee, G., Odom, S., \& Wolery, M. (2005). The use of single-subject research to identify evidence-based practice in special education. Exceptional Children, 71(2), 165-179. http://dx.doi.org/10.1177/001440290507100203

Hudson, P., \& Miller. S. P. (2006). Designing and implementing mathematics instruction for students with diverse learning needs. Boston: Pearson/ Allyn and Bacon.

Kazdin, A. E. (2011). Single-case research designs: Methods for clinical and applied settings $\left(2^{\text {nd }}\right.$ ed.). New York: Oxford University Press.

McIntosh, A. (2008). Förstå och använda tal - en handbok. Nationellt centrum för matematikutbildning. (Understand and use numbers - a handbook. National center for mathematics education) Göteborgs universitet: Göteborg.

Ok, M. W., \& Bryant, D. P. (2015). Effects of a Strategic Intervention With iPad Practice on the Multiplication Fact Performance of Fifth-Grade Students With Learning Disabilities. Learning Disability Quarterly. http://dx.doi.org/10.1177/0731948715598285

Plavnick, J. B., \& Ferreri, S. J. (2013). Single-Case Experimental Designs in Educational Research: A Methodology for Causal Analyses in Teaching and Learning. Educational Psychology Review, 25(4), 549-569. http://dx.doi.org/10.1007/s10648-013-9230-6

Rathmell, E. C., \& Gabriele, A. J. (2011). Number and operations: Organizing your curriculum to develop computational fluency. I Fennell (Ed.) Achieving fluency: special education and mathematics (105-141). Reston, VA: National Council of Teachers of Mathematics. 


\section{Macrothink}

Journal of Education and Training

ISSN 2330-9709

Re, A., Pedron, M., Lucangeli, D., \& Tressoldi, P. (2014). Response to specific training for students with different levels of mathematical difficulties. Exceptional Children, 80(3), 337-352. http://dx.doi.org/10.1177/0014402914522424

Samuelsson, J. (2006). ICT as a change agent of mathematics teaching in Swedish secondary school. Education and Information Technologies, 11, 71-81.

Tsui, J. M., \& Mazzocco, M. M. (2006). Effects of Math Anxiety and Perfectionism on Timed versus Untimed Math Testing in Mathematically Gifted Sixth Graders. Roeper Review, 29(2), 132-139.

\section{Copyright Disclaimer}

Copyright reserved by the author(s).

This article is an open-access article distributed under the terms and conditions of the Creative Commons Attribution license (http://creativecommons.org/licenses/by/3.0/). 